\title{
Research and Enlightenment of Xinjiang Safety Education Material
}

\author{
Wu Zhimin \\ Xinjiang Forestry School, Urumuqi, Xinjiang, 830000 China
}

Keywords: safety education; Xinjiang; local; teaching material

\begin{abstract}
The unique geographical situation and cultural status of Xinjiang determine the particularity and difficulty of the education security work in Xinjiang. Education local safety education textbook "Student Safety Education" fails to meet the requirements of "practicality and effectiveness" of "Education Guidelines for Public Safety in Primary and Secondary Schools", and also fails to meet the work requirements of education safety in Xinjiang, resulting in redundant knowledge and not meeting the needs of students. Only when we return to education and follow the three principles of practicality, connectedness and systematization, can we improve the safety education course continuously, so as to achieve the purpose of teaching, learning and using.
\end{abstract}

\section{Introduction}

The constant changes in social structure and profound changes in ideology have put forward new requirements for the safety and stability of primary and secondary schools. People gradually formed the education concept of development of security. Safety education has also gradually developed into a discipline. Xinjiang is located in the hinterland of the Eurasian continent. It borders eight countries and has 55 ethnic groups. It is this geographical and cultural situation that determines the particularity and difficulty of the work of education security in Xinjiang. Xinjiang security education urgently needs to establish a more perfect regional security education system and develop more reasonable safety education textbooks. There are a lot of problems in the education teaching material "education of student safety" in Xinjiang. Considering and reflecting on the problems in the textbooks is conducive to improving the safety education textbook system in Xinjiang.

Maslow's hierarchy theory says that the need for security is the most basic human need. Security is closely related to human survival and development. The education guidelines for public safety in primary and secondary schools affirmed the importance of education and mentioned the goal of public education. Safety education can be divided into two dimensions according to the acquisition degree and connotation -- vertical: safety knowledge, safety skills, safety habits, safety attitude, safety responsibility and safety awareness. Horizontal: life safety education, physical and mental health education, social life security education, national defense security education, natural disaster security education, etc.

\section{Brief Introduction of the Textbook Education for Student Safety}

Student safety education was published by Xinjiang education publishing house. It was approved by the Xinjiang teaching materials commission in 2014 and published the first edition in January 2014.It has been used as the whole Xinjiang safety education textbook until now, and now it is the 4th edition in 2017.There are 4 textbooks in this series -- grade 1 to grade 3, grade 4 to grade 6 , grade 7 to grade 9 and senior high school, respectively designed by first-line teachers of key schools in primary schools, junior middle schools and senior high schools according to the physical and mental development characteristics of students. Each volume consists of four parts: case and enlightenment, countermeasures, communication and practice, knowledge expansion and so on.

According to the teaching Suggestions in the foreword of this textbook, the textbook is based on the education guidelines for public safety in primary and secondary schools and is compiled according to the actual situation in Xinjiang and the characteristics of students. In use with "moral character and life" textbook combination. Safety education content and class schedule are decided 
by teachers, and meanwhile, practicality, practicality and fun are emphasized.

\section{Problems and Suggestions in the Preparation of Education Textbooks}

\subsection{Problems in the textbook education for student safety}

\subsubsection{The arrangement is not reasonable}

According to the guarantee mechanism of education guidelines for public safety in primary and secondary schools, "the time of education in public safety should be ensured A combination of curriculum penetration and the use of local curriculum time "[1]. In the preface of the book, it is mentioned that "the combination of teaching materials and teaching materials of moral character and life" is arranged by teachers, which may cause the teaching time of education cannot be guaranteed. In addition, it can be seen from the division of textbooks and grades that a textbook should be used for 3 years and distributed to students in the first year. It is difficult to guarantee that the textbook will not be lost, and this compilation method is not conducive to the implementation of textbooks.

\subsubsection{The purpose of the course is not clear, and the activities are not practical}

For example, in chapter 5, lesson 1, grade 4-6 [2], students first learned the matters needing attention of group outing, travelling, diet, clothing and medicine. Second, a student was hospitalized for touching a poisonous plant. After that, I designed an exercise and asked students to design a safe travel plan for the whole class of the fourth grade. Education security is based on practice. This module should play a leading role. The author thinks that the following design can be carried out:

1) We have students and teachers in the class of grade _.

2) Time _____ accommodation? Weather conditions you will wear clothes.

3) Please make sure the car is in the teacher's charge.

4) Make sure to eat _ food and water_ bottles on the way.

5) Urgently needed medicine:

6) In charge of directing _ students, __ teachers,

7) What might happen? (student discussion)

8) What preparations should be made and how to act....

9) The travel slogan _ _ how to contact others, make sure that every student is not left behind.

10) So what else is unaccounted for?

\subsubsection{Deviation between reality and demand.}

(1) It is not consistent with students' abilities.

Education guidelines for public safety of primary and secondary schools mentioned that "primary schools focus on games and simulation, junior middle schools focus on activities and experiences, and senior high schools focus on experience and differentiation". Only part of the students' words in the reading books of grade 1 to grade 3 in this textbook are marked in pinyin, which poses a challenge to the students who enter primary school to use this book properly.

(2) It is not in accordance with students' needs

In the book, the health and safety problems are illustrated by the examples of mutton skewers and other delicacies with Xinjiang characteristics, and the life safety problems are illustrated by the news examples with regional characteristics, such as the Xinjiang earthquake. However, there is still room for improvement. For example, the second section of chapter ii of the textbook for grade 7 9 -- passing the youth flower season. Among them, it refers to the problem of acne, which is a hot topic for male and female students. The traditional requirement of not eating spicy food and not getting cold cannot meet the requirements of students. On the problem of acne, students are willing to know more, such as how to reduce inflammation and how to use skin care products correctly.

(3) It is not in conformity with regional requirements

The content of education in the textbooks of Xinjiang edition is quite lacking. It only appeared in 
the high school level, which resulted in the lack of education in the national security. National security education should be a long-term task. We have learned to sing the national anthem and team songs since childhood. We can help students to understand the meaning of national security gradually from the understanding of national flags, red scarves and group emblems to the understanding of the territory of China and Xinjiang, to the understanding of national conditions and political environment. Many problems should be taught through different teaching methods in primary and middle schools, while in high schools, students should have an overall understanding of national security.

\subsubsection{The content of the textbook is repetitive and miscellaneous}

(1) The knowledge points are simply listed, and the teaching content is very important.

For example: the second chapter $7 \sim 9$ grade prevention cure reasonable diet safe drug use in the first section, the teaching material using three case studies: SARS cases, students collective poisoning happen vomiting, dizziness, abuse of drugs lead to vision loss, after knowing case told the students the food safety precautions (such as: cooked separately, poisoning organization itself), drinking water safety matters aging liters (don't drink, don't drink water), medication items (not to be advertising to take medicine, medicine instruction "disable" meaning "careful", etc.).We should tell the students the importance of safety awareness. We should tell the students that they should report their illness to the teachers. We should tell students the importance of seeing doctors and getting medicine in regular hospitals and pharmacies. You can use a copy of the directions page to teach students how to read the directions and how to use them. First of all, we should make students develop the awareness that parents are the guardians of students and teachers are the guardians of students in schools. Secondly, students should have a correct and overall understanding of drugs.

(2) Inadequate teaching resources

In grade 1 to grade 3 of the textbook, there is an appendix to show students common safety signs and emergency telephones, while the latter textbooks have an appendix. The appendix can provide students with relevant reference books or guides. This part can develop teaching resources to help students expand their knowledge. The editor can edit the safety education picture books of students in the appendix, which can be supplemented by CD-ROMs, PPT and video materials for teachers' teaching.

\subsection{Suggestions on the Preparation of the Education Textbooks for Student Safety}

We should supplement the materials to improve the textbook. The education theme module of national security also needs to be reorganized according to the stage of students' learning and understanding ability. National security education should be the center of this course. Textbooks should provide students with more educational and fun Spaces to enhance national security. We should also pay attention to practicality. What students pay attention to should be added to the textbook. For example, we guarantee the authenticity of all kinds of instructions, maps, etc. We also need students to actually manipulate what they're learning; we should inspire and guide students to practice. The situational teaching, we set up is beneficial to students' training behavior. In the aspect of textbook compilation: 1 . The textbook should provide the creation scheme of the practical experience environment, such as creating a scene for students to find sensitive objects or states in the scene, so that each student can establish crisis awareness.2. The content design can adopt thematic style, reuse the picture information, and integrate the knowledge points into the picture for students to analyze. With the increase of the grade, keep digging the security connotation of the same theme pictures, and improve the students' understanding of security with the improvement of their intelligence level.

\section{Conclusion}

Education is the first set of local safety education textbooks in Xinjiang, and its theoretical and practical significance is worthy of affirmation. To solve the problems in the textbook, it is necessary to return to the purpose of education security. Several principles should be followed: 


\subsection{Practical principle.}

All subjects have infiltrated the content of safety education, and special courses should highlight the characteristics of safety education -- "practicality, practicability and effectiveness" [2]. Compared with the construction of knowledge framework, this course should focus on operation. The introduction of knowledge points, the setting of thinking questions and the setting of after-class activities should be instructive. Teaching materials should guide students to participate, and students should take the initiative to practice themselves and get to know the truth.

\subsection{Associative principle.}

Not only education for defense security, but all courses should be conducted in depth throughout the grade of the textbook, rather than repeated. We should pay attention to the connection between textbooks for different grades. Textbook writers should break the shackles of institutions. We should focus on writing links between members. This is beneficial to avoid the repetition of the textbook content and the isolation of the teaching content of junior high school.

\subsection{System principle.}

We should pay attention to the systematic improvement of safety literacy of teachers, parents and students. The teacher certification certificate does not specifically set safety education teachers. Most of these positions are held by teachers of school thought and politics. The teachers of ideological and political courses are mostly liberal arts students, who have little understanding of the safety of science experiments and other problems. Therefore, teachers of all subjects should improve safety quality and be familiar with safety education. We should pay attention to the systematization of education resource integration and develop supporting family textbooks to encourage parents to play a promoting role in student safety education.

\section{References}

[1] The general office of the state council general office of the state council on forwarding public security education of primary and secondary schools guidelines to inform [ED/OL]. The ministry of education of the People's Republic of China. 2007-02-07. [r].2018-07-22, 13:00, http://www.moe.edu.cn/jyb_xxgk/moe_1777/moe_1778/tnull_27696.html, 2018-07-22

[2] Zhu Xuehong, Tian Zheng, Gao Ximei, et al. Student safety education [Z]. Xinjiang: Xinjiang education publishing house, 2017. 